Www.jmscr.igmpublication.org

Index Copernicus Value: 79.54

ISSN (e)-2347-176x ISSN (p) 2455-0450

crossrefDOI: https://dx.doi.org/10.18535/jmscr/v7i1.144

Journal Of Medical Science And Clinical Research

IGM Publication

An official Publication of IGM Publication

\title{
Evaluation of hearing in the OPD patients at a tertiary care centre
}

\author{
Authors \\ Dr Raghvendra Singh Gaur, Dr Swati Chandel, Dr Prashant \\ CM Medical College \\ Email: dr.raghu007@gmail.com, Mobile: 7509684796
}

\begin{abstract}
Introduction: Hearing makes man a social being, those who are hard of hearing cannot express themselves because of lack of ability to speak. Hearing impairment at any age has serious effects on the day to day life of an individual and he/she feels handicapped socially, emotionally, and scholastically. It is a common chronic impairment, particularly in the older adults, there are many causes which may lead to hearing impairment and is known to vary from place to place and country to country in both sexes with advancing age. There is scarcity of such information in India; this gave us the idea to undertake a study on hearing impairment in the local population who are attending the ENT OPD at this tertiary care centre.

Aims and Objectives: To assess the hearing status in different age groups who attended the ENT OPD at the tertiary level in eight months with complaints of hearing impairment.

Study Design: Retrospective study.

Material and Methods: This study was conducted in the Department of ENT of a tertiary care hospital, in which audiometry records were analysed to see the status of hearing and data segregation was done according to age, sex and involvement of the side of the ear (right or left).

Result: 459 audiometry records were analysed in this study out of which the youngest patient was 8 years old and oldest one was 84 years old. Surprisingly in this study male patients with hearing complaints attending the OPD (as per the records) were less that is 209 (45.5\%) compared to the female that is 250 (54.5\%). Maximum number of patients attending the ENT OPD belonged to the age group of 21-30 (108 in number) and least number belonged to the age group of 81-90 years i.e only 1.

Conclusion: We know hearing problems increase as the age progresses and males are affected more than females but in this study paradoxical observation was recorded.

Keywords: Hearing impaired, PTA.
\end{abstract}

\section{Introduction}

Hearing impairment is one of the common forms of sensory disorder in humans. There were many studies conducted in the past to evaluate various factors like occupational trauma, noise trauma, drugs, and effect of smoking and organic solvent exposure which can lead to hearing impairment, besides this, effect of presbycusis and sex on hearing impairment has been studied by various authors. According to the Beaver Dam cohort in the United States, the prevalence of hearing loss, increased steadily with age ${ }^{1}$ and according to the World Health Organization, hearing loss affects 538 million people Worldwide ${ }^{2}$. Because hearing impairment is known to vary from place to place and country to country in both the sexes and with 
increasing age, we decided to assess the status of hearing in the patients attending the ENT OPD with the complaints of hearing impairment using pure tone audiometry. In this study we aimed to study the incidence, age and sex distribution of hearing loss.

\section{Materials and Methods}

This study was carried out in the Department of ENT and Head \& Neck Surgery at a tertiary care centre. Audiometry records of the patients presented to the ENT OPD with the complaints of hearing impairments during eight months were analysed. Total 459 records of audiomentry were included in the study. The hearing test was carried out in a sound proof room with the help of ELKON EDA 3N3 audiometer, and degree of impairment is charted in the form of a graph called audiogram at different frequencies. Usually air conduction is measured for tones of 125 , $250,500,1000,2000,4000$ and $8000 \mathrm{~Hz}$ and bone conduction thresholds for 250, 500, 1000, 2000, and $4000 \mathrm{~Hz}$. The difference in thresholds of AC and $\mathrm{BC}$ is a measure of degree of conductive deafness. When difference between 2 ears is 40 $\mathrm{dB}$ or above in $\mathrm{AC}$ thresholds, the better ear is masked to avoid getting a shadow curve for the non test better ear. Records were segregated according to the age, sex and right $\&$ left ear.

\section{Results}

Total 459 patient records were analysed in the study out of which the youngest patient was 8 yrs old and the oldest one was 84 yrs old. Out of 459 records, 209 (45.5\%) were male and 250(54.5\%) were female.

Table 1 shows distribution of patients with hearing impairment in different age groups and its percentage. Maximum numbers of patients were seen in the age groups of $21-30$ and minimum number in 81 - 90. Reason may be younger patients are able to go to the medical centres more easily then elders, it shows the dependency of kids and old people on their family to seek health care.
Table 1: Age distribution

\begin{tabular}{|l|c|c|}
\hline Age group (years) & No. Of Patients & Percentage \% \\
\hline $1-10$ & 11 & 2.4 \\
\hline $11-20$ & 59 & 12.8 \\
\hline $21-30$ & 108 & 23.5 \\
\hline $31-40$ & 75 & 16.34 \\
\hline $41-50$ & 100 & 21.7 \\
\hline $51-60$ & 50 & 10.8 \\
\hline $61-70$ & 45 & 9.8 \\
\hline $71-80$ & 10 & 2.1 \\
\hline $81-90$ & 1 & 0.1 \\
\hline
\end{tabular}

Table 2 shows sex distribution in male and female in different age group. Sex distribution shows females were more aware of their hearing problems and sought health care more and in majority of group's number of females were more than the male.

\section{Table 2}

\begin{tabular}{|l|c|c|c|}
\hline Age group & Male & Female & Ratio \\
\hline $1-10$ & 8 & 3 & $2.66: 1$ \\
\hline $11-20$ & 26 & 33 & $0.78: 1$ \\
\hline $21-30$ & 45 & 63 & $0.71: 1$ \\
\hline $31-40$ & 23 & 52 & $0.44: 1$ \\
\hline $41-50$ & 48 & 52 & $0.92: 1$ \\
\hline $51-60$ & 23 & 27 & $0.85: 1$ \\
\hline $61-70$ & 29 & 16 & $1.81: 1$ \\
\hline $71-80$ & 6 & 4 & $1.5: 1$ \\
\hline $81-90$ & 1 & 0 & $1: 0$ \\
\hline
\end{tabular}

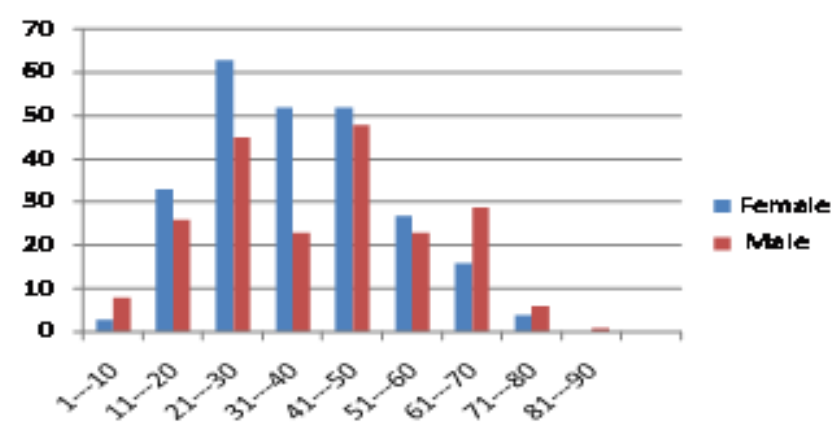

Table 3 shows the degree of hearing impairment in right ear: out of total number of patients majority had normal hearing, followed by mild hearing loss then moderate, moderately severe, severe and profound.

Table 3

\begin{tabular}{|l|c|}
\hline Degree of hearing impairments & Numbers of patients \\
\hline Normal & 250 \\
\hline Mild & 119 \\
\hline Moderate & 55 \\
\hline Moderately sever & 20 \\
\hline Sever & 13 \\
\hline Profound & 2 \\
\hline
\end{tabular}




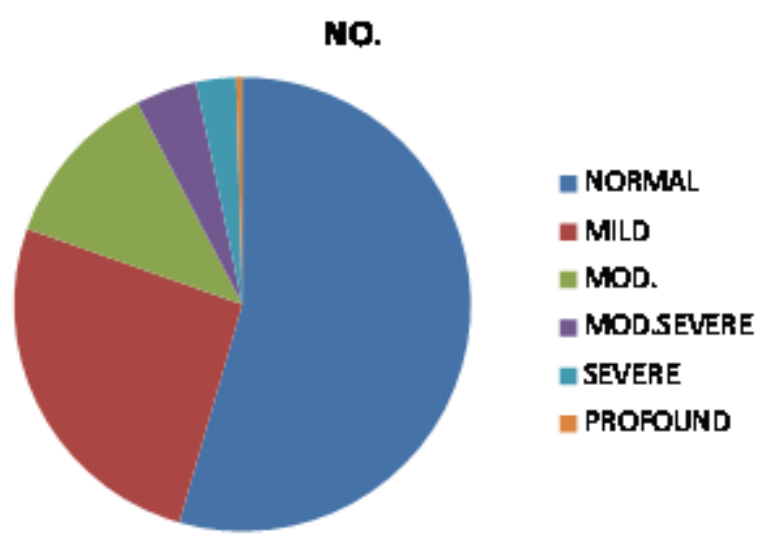

Table 4 shows the degree of hearing impairment in left ear, this again shows the same trend of hearing status as the previous one.

\section{Table 4}

\begin{tabular}{|l|c|}
\hline Degree of hearing impairment & Numbers of patients \\
\hline Normal & 253 \\
\hline Mild & 107 \\
\hline Moderate & 60 \\
\hline Moderately severe & 22 \\
\hline Severe & 14 \\
\hline Profound & 3 \\
\hline
\end{tabular}

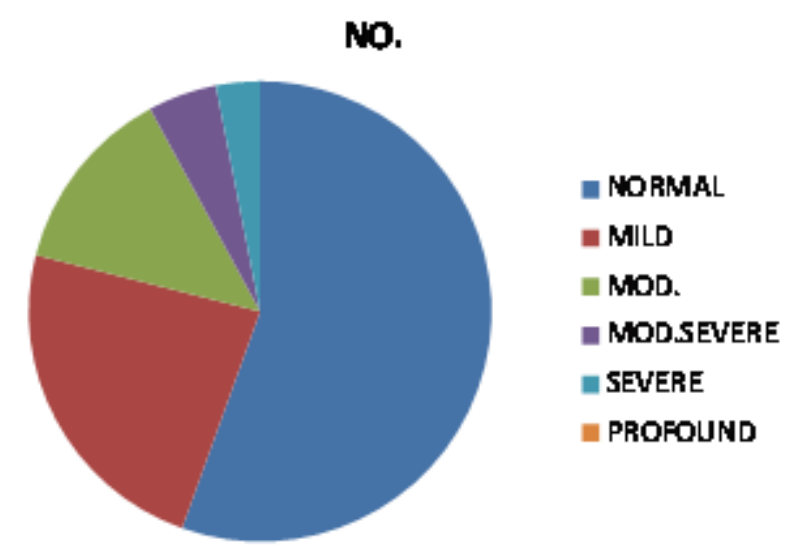

\section{Conclusion}

This study was conducted to show the present scenario of the hearing problem in local region and we have not segregated data too much to make this study simple. Health care planner should keep the fact in their mind to address this paradoxical trend. These patients belonged to different communities and were of different age groups and gender. Pure tone audiogram is a non invasive technique to determine the degree and type of hearing loss. It is used as a first line investigation for evaluation of various ear disorders like ASOM, CSOM, Otosclerosis, presbycusis, and other cochlear and retrocochlear pathology. By this technique early identification of hearing loss can be assessed and quantified which can be followed by immediate and appropriate interventions which result in better language, speech and social development. Mishra et $\mathrm{al}^{3}$ had found the higher incidence of hearing problem in males, but in our study it has been observed that as the age increases the number of the patients seeking healthcare decreased. This observation in our study makes it difficult to comment on the fact that," hearing problem increases as the individuals age increases." According to WHO census, the majority of disabilities related to the hearing belong to the adults $(91 \%)$ and children contribution is only $9 \%$. In one study prevalence of hearing loss is more in the age group above 65 years ${ }^{4}$, but some studies shows that age group of 50 years and above are involved more in number than other age groups. It's a well known fact that aging causes deterioration of hearing mechanism at cochlear and retrocochlear region and majority of individuals suffer from this problem but they do not come to seek the health care to resolve the issue. The reasons may be multiple like dependency of elderly and young population on the other family members, poor knowledge of the health related issues, lack of infrastructure to diagnose and treat such patients, poverty, unacceptance of the hearing aid in general public.

National Institute on Deafness and other Communication Disorders (NIDCD) states that $15 \%$ of the population is having hearing loss due to loud noise in the work place or due to prolonged use of mobile phones ${ }^{5}$. Prolonged use of mobile phones for more than 30 minutes can cause $10 \mathrm{~dB}$ transient hearing $\operatorname{loss}^{6}$. As per the available information, about $6.3 \%$ of the Indian population is suffering from hearing impairment, among these; the rural population is more commonly affected than the urban population ${ }^{7}$. Hearing loss in children may affect their education due to the defective development of perceptual 
and linguistic abilities, because of reduced aural input. Morbidity due to hearing loss in paediatric age group is inversely proportional to the literacy of parents. Most common causes for deafness in paediatric age group are related to the infections, and it is more prevalent in low socioeconomic status and families with illiteracy. Infection is the most common cause for hearing loss in developing countries according to WHO. Hearing loss gives rise to a number of disabilities. Several studies have shown that uncorrected hearing loss gives rise to poorer quality of life, reduced social activity, and a feeling of being excluded, leading to an increased prevalence of symptoms of depression. These findings indicate the importance of early identification of hearing loss and of providing rehabilitative support, where the fitting of hearing aids is usually an important component. Robinovich has stated that early identification of hearing loss and adequate corrective measures help in better speech, language, social, psychological and educational development and a more satisfactory outcome ${ }^{8}$. More recently Dr. Frank Lin and his colleagues at Johns Hopkins University found a strong relationship between degree of hearing loss and risk of developing Dementia. Patients with mild degree hearing loss have 2 times, moderate degree 3 times and severe degree have 5 times the risk than normal hearing individuals ${ }^{9}$. Although it occurs in an increasing prevalence with age, hearing loss is often ignored during the diagnosis and treatment of cognitive and memory disorders in elderly patients.

This study calls for further research to understand and study the gap between hearing impaired individuals and available health care system.

\section{References}

1. Nash SD, Cruickshanks KJ, Klein R, et al. The prevalence of hearing impairment and associated risk factors: the Beaver Dam Offspring Study. Arch Otolaryngol Head Neck Surg 2011; 137:432.
2. Stevens G, Flaxman S, Brunskill E, et al. Global and regional hearing impairment prevalence: an analysis of 42 studies in 29 countries. Eur J Public Health 2013; 23:146.

3. Mishra R. N. and Bhatia M. L.; Plastic surgery of the sound conducting apparatus of the ear; p. 23.

4. Taneja, M.K. (2014) Deafness a Social Stigma: Physician Perspective. Indian Journal of Otolaryngology and Head \& Neck Surgery, 66, 353-358.

5. Health Info Statistics and Epidemiology. Quick Statistics, National Institute on Deafness and other Communication Disorders (NIDCD). http://www.nided.nih.gov/health/statistics/ pages/quick.aspx

6. Ramya, C.S., Karthiyanee, K. and Vinutha, S. (2011) Effect of Mobile Phone Usage on Hearing Threshold: A Pilot Study. Indian Journal of Otology, 17, 159161. http://dx.doi.org/10.4103/09717749.94494

7. National Programme for Prevention and Control of Deafness (NPPCD) Operational Guideline. http://mohfw.nic.in

8. Nogueria, J.C.R. and da Conceicao Mendonca, M. (2011) Assessment of Hearing in a Municipal Public School Student Population. Brazilian Journal of Otorhinolaryngology, 77 (6).

9. Lin, F.R., Metter, E.J., O’Brien, J.R., Resnick, S.M., Zonderman, A.B. and Ferrucci, L. (2011) Hearing Loss and Incidence of Dementia. Archives of Neurology, 68, 214-220. http://dx.doi.org/10.1001/archneurol.2010. 362 